\title{
Uso industrial de grãos de cevada de lavouras dessecadas em pré-colheita
}

\author{
Eduardo Caierão(1) e Adão da Silva Acosta(2)
}

(1)Embrapa Trigo, BR 285, Km 294, Caixa Postal 451, CEP 99001-970 Passo Fundo, RS. E-mail: caierao@cnpt.embrapa.br (2)Embrapa
Transferência de Tecnologia, BR 285, Km 294, Caixa Postal 451, CEP 99001-970 Passo Fundo, RS. E-mail: adao@cnpt.embrapa.br

Resumo - O objetivo deste trabalho foi avaliar o impacto da antecipação da colheita de lavouras de cevada sobre a germinação dos grãos, ao longo de 12 meses de armazenamento. O ensaio de campo foi realizado em 2002 e 2003. As parcelas colhidas foram armazenadas nos anos subseqüentes aos dos ensaios em campo, e a germinação foi monitorada mensalmente. Os tratamentos avaliados foram: dessecação com os princípios ativos glifosato e paraquat, nas doses 1, 1,5 e $2 \mathrm{~L} \mathrm{ha}^{-1}$, além das testemunhas, colhidas normalmente e de forma antecipada, sem dessecação. O delineamento utilizado foi o de blocos ao acaso, com três repetições. A colheita antecipada sem dessecação foi o tratamento de maior prejuízo qualitativo à germinação dos grãos. A deterioração qualitativa temporal dos grãos, nos tratamentos com herbicidas dessecantes, foi estatisticamente similar à observada nas amostras oriundas da testemunha colhida normalmente, sem dessecação. Não foram encontradas evidências de que o uso de herbicidas dessecantes acelere o processo de perda de germinação de grãos de cevada, ao longo do período de armazenagem, para os produtos e doses testados.

Temos para indexação: Hordeum vulgare, germinação, dessecante, glifosato, paraquat.

\section{Industrial suitability for malting of grains from desiccated pre-harvest barley}

\begin{abstract}
The objective of this work was to assess the impact of early harvesting of barley on grain germination, along 12 months of storage. A field trial was carried out in 2002 and 2003 . The plot yields were stored during the years subsequent to the field trial, and germination was monitored monthly. The following treatments were evaluated: desiccation with glyphosate and paraquat, at 1, 1.5, and $2 \mathrm{~L} \mathrm{ha}^{-1}$, and the checks, which were normal and early harvest without desiccation. A randomized block design with three replications was utilized. The early harvest without desiccation treatment had the greatest quality loss regarding grain germination. Qualitative deterioration of grains within time was statistically similar both in treatments with desiccation and those with normal harvest without desiccation. No evidence was found to prove that the use of desiccating herbicides accelerates the process of loss of barley grains germinating power during the storage period, as far as the products and doses tested are concerned.
\end{abstract}

Index terms: Hordeum vulgare, germination, desiccant, glyphosate, paraquat.

\section{Introdução}

A cevada cervejeira é uma excelente alternativa de cultivo para o inverno na Região Sul do Brasil (Árias, 1995). Entre seus principais benefícios, destacam-se a precocidade, a liquidez e a rentabilidade. A área fomentada com esse cereal no país oscila em torno de 100 mil hectares (IBGE, 2007), conforme a política de compra definida pelas empresas malteiras e previsões climáticas do ano (Caierão et al., 2005).

A cevada caracteriza-se por ser altamente sensível a precipitações pluviométrias no momento da colheita, principalmente pelo prejuízo promovido à germinação de grãos (Reuss et al., 2003). A manutenção do poder de germinação dos grãos em pós-colheita é essencial para a viabilidade do processo de malteação, onde há a transformação da cevada em malte, que é utilizado como insumo primário na fabricação de cerveja (Jacobsen et al., 2002). A desuniformidade na maturação, intrínseca à cultura é, em muitas situações, acentuada por práticas de manejo inapropriadas, como a adubação nitrogenada de cobertura tardia (elongação), que induz o acamamento e o rebrote (Masle, 1985; Reunião Anual de Pesquisa de Cevada, 2005). Como forma de superar esses problemas, muitos produtores têm optado pela 
dessecação da lavoura com herbicidas, para uniformizá-la e antecipar a colheita (Lacerda et al., 2001).

Gomes (1982) utilizou o princípio ativo paraquat para dessecação de soja e obteve sementes de melhor qualidade, em comparação às que não passaram por dessecação. Com essa mesma cultura, Lacerda et al. (2003) relataram que a aplicação do glufosinato de amônio reduziu os valores de germinação nas sementes, em comparação com outros produtos (paraquat e glifosato). No entanto, Inoue et al. (2003) encontraram resultados opostos, pois o glufosinato de amônio foi o único herbicida a não depreciar as características qualitativas da soja, em relação a outros produtos testados. Agostinetto et al. (2001) relataram, em pesquisa com arroz, que herbicidas não seletivos como o paraquat, o glufosinato de amônio e o glifosato, quando aplicados na maturação fisiológica dos grãos, não afetaram as características qualitativas desse cereal; além disso, não observaram efeitos significativos de doses e época de aplicação desses produtos. Ao trabalhar com feijão, Miguel (2003) não observou prejuízos qualitativos na semente, após a aplicação do herbicida dessecante paraquat aos 28, 32, 36, 40 e 44 dias após a floração, diferentemente do encontrado para o glifosato, que só não interferiu na germinação das sementes quando aplicado tardiamente (aos 44 dias após a floração). No mesmo estudo, ao avaliar o efeito do herbicida dessecante glufosinato de amônio, Miguel (2003) relatou que prejuízos qualitativos foram verificados em todas as épocas de dessecação.

Trabalhos com trigo, cevada e canola indicam que há variabilidade na germinação e no vigor das sementes, quando dessecadas com o princípio ativo glifosato que, aplicado ainda durante o processo de maturação, se acumula no embrião e ocasiona anormalidades no seu desenvolvimento (Cessna et al., 2002). Trabalhos realizados por Moore \& Jettner (2007) mostraram que a viabilidade e o vigor das sementes de cevada foram reduzidos quando o glifosato foi aplicado no momento em que a lavoura apresentava grãos com $40 \%$ de umidade; no entanto, em sementes de trigo, não houve quaisquer alterações sobre essas mesmas características. Baig \& Gamache (2006), ao avaliar o comportamento de herbicidas dessecantes, em diferentes culturas e situações, concluíram que, em razão da variabilidade na maturação das lavouras, a utilização da dessecação não é benéfica. Segundo esses autores, há alto risco de redução nos componentes vitais dos grãos. Considerando-se que a cultura da cevada tem como pré- requisito a necessidade de grãos viáveis e com alto vigor para a malteação, os riscos seriam, logicamente, maiores.

Como a cevada é malteada durante todo o ano, além de não interferir sobre a germinação e o vigor das sementes, $\mathrm{o}$ uso de herbicidas dessecantes não pode acelerar a deterioração dos grãos durante o período de armazenamento, em comparação com a observada em grãos colhidos sem uso de herbicida. Em soja, por exemplo, sementes dessecadas e armazenadas por seis meses não apresentaram qualidade fisiológica aceitável (Lacerda et al., 2003).

A aplicação de herbicidas dessecantes, no final do ciclo da cultura da cevada, pode facilitar o manejo das lavouras por parte dos produtores. Considerando-se que existem produtos comerciais com a molécula glifosato, registrados para uso em cevada cervejeira com a finalidade de dessecação, e que empresas malteiras e cervejeiras de vários países restringem seu uso (Hanson \& Graf, 2007), este trabalho teve como objetivo avaliar o impacto da utilização desse produto e do paraquat, sobre a germinação de grãos de cevada, e a manutenção da qualidade para malteação durante 12 meses de armazenagem.

\section{Material e Métodos}

Os ensaios foram realizados nos anos de 2002 e 2003, na área experimental da Companhia Brasileira de Bebidas, em Passo Fundo, RS, em delineamento de blocos ao acaso, com três repetições. A cultivar utilizada nos experimentos foi a MN 698. Foram testados oito tratamentos: 1, glifosato $1 \mathrm{~L} \mathrm{ha}^{-1} ; 2$, glifosato $1,5 \mathrm{~L} \mathrm{ha}^{-1} ; 3$, glifosato $2 \mathrm{~L} \mathrm{ha}^{-1}$; 4 , paraquat $1 \mathrm{~L} \mathrm{ha}^{-1} ; 5$, paraquat $1,5 \mathrm{~L} \mathrm{ha}^{-1} ; 6$, paraquat $2 \mathrm{~L} \mathrm{ha}^{-1} ; 7$, testemunha colheita normal não dessecada (TCN); e 8, testemunha colheita antecipada não dessecada (TCA). Todos os tratamentos com herbicidas dessecantes foram aplicados entre os estádios 11.2 e 11.3 da cultura (massa mole a massa dura), definido pela escala de Large (1954). A colheita dos tratamentos foi realizada no estádio 11.4 (grão maduro, palha morta), com exceção da TCA, em que a colheita foi realizada entre os estádios 11.2 e 11.3, da mesma escala. Cada parcela experimental foi constituída por $10,5 \mathrm{~m}^{2}$ de área útil.

Os ensaios foram estabelecidos conforme as indicações técnicas para o cultivo da cevada (Reunião Anual de Pesquisa de Cevada, 2005). A adubação foi realizada de acordo com os dados da análise química do solo, e foram feitas duas aplicações da mistura Pyraclostrobin + Epoxiconazole (Opera 0,75 L ha $\left.{ }^{-1}\right)$, nos estádios 10 (emborrachamento) e 10.5.1 (início do florescimento) da escala fenológica de Large (1954). 
Os tratamentos com dessecantes foram aplicados entre $10 \mathrm{~h}$ e $11 \mathrm{~h} 30$, com auxílio de pulverizador costal pressurizado a $\mathrm{CO}_{2}$. Para a operação, foram utilizados bicos de jato plano do tipo leque, série 110.03 , tendo-se mantido pressão constante de $\mathrm{CO}_{2}$ a $150 \mathrm{kPa}$ e velocidade de deslocamento de $3,5 \mathrm{~km} \mathrm{~h}^{-1}$, o que propiciou a aplicação do volume de calda de $200 \mathrm{~L} \mathrm{ha}^{-1}$.

As parcelas foram colhidas manualmente, e os grãos foram armazenados por repetição em câmara de armazenagem, em condições controladas de umidade $(13 \%)$ e temperatura $\left(18\right.$ a $\left.20^{\circ} \mathrm{C}\right)$, tendo-se simulado as condições de armazenagem industrial, durante 12 meses. Mensalmente, uma amostra de grãos de cada repetição dos tratamentos armazenados foi coletada e enviada ao laboratório de qualidade da Maltaria Navegantes, em Porto Alegre, para determinação da germinação.

As análises de germinação foram realizadas durante todo o ano de 2003, referentes ao ensaio colhido em 2002, e 2004, referentes ao ensaio colhido em 2003. A determinação da germinação foi realizada conforme metodologia descrita pelo European Brewing Convention, utilizado comumente pelas empresas malteiras. Para tanto, 100 sementes foram embebidas em papel umedecido com $4 \mathrm{~mL}$ de água, em placa de Petri, por três dias e, posteriormente, foram avaliadas quanto ao porcentual de grãos germinados.

Os dados coletados foram submetidos à análise da variância, tendo-se considerado os fatores de variação ano, mês e tratamento, arranjados em esquema fatorial. $\mathrm{O}$ fator mês foi decomposto dentro de cada tratamento, por meio de regressão, a partir da linearização dos dados, conforme a seguinte equação: $Y=\log [-\log ((1-X) 5)]$; em que: $X$ refere-se ao dado original da variável germinação e Y refere-se aos dados da variável germinação linearizados.

As médias dos tratamentos, dentro de cada mês de avaliação, foram classificadas conforme faixas de especificação utilizadas no recebimento da cevada, que definem a aptidão do produto e o valor a ser pago. Assim, empregou-se: o algarismo I, para classificar médias de germinação superiores a 95\%; o algarismo II para médias de germinação entre 90 e 95\%; e III para médias de germinação inferiores a $90 \%$.

Para avaliação do efeito dos herbicidas dessecantes sobre a qualidade da cevada, utilizou-se como referência o tratamento 7 (TCN), representativo do procedimento usual dos produtores, e o tratamento 8 (TCA), representativo de uma das práticas adotadas para escapar das chuvas na colheita.
Os valores beta das equações de regressão dos tratamentos foram comparados por meio de contrastes ortogonais, tendo-se utilizado o teste t. Foram determinados os efeitos da TCN em relação à TCN (contraste $1-\mathrm{C}_{1}$ ) e da TCN em relação à TCA (contraste $2-\mathrm{C}_{2}$ ), conforme modelos a seguir: $C_{1}=\beta_{1}+\beta_{2}+\beta_{3}+\beta_{4}+\beta_{5}+\beta_{6}-6 \beta_{7}$ e $C_{2}=\beta_{7}-\beta_{8} ;$ em que $\beta$ é o coeficiente angular das retas de cada um dos tratamentos avaliados no ensaio. A estimativa dos contrastes foi realizada, independentemente, para cada um dos anos de avaliação.

Embora na análise da variância os anos tenham sido considerados como fator (para a verificação de possíveis interações), na interpretação dos dados foram caracterizados como variável independente (aleatória).

\section{Resultados e Discussão}

A análise da variância revelou interação significativa entre os fatores ano, mês e tratamento (Tabela 1).

Para a compreensão da interferência do fator ano, na significância da interação tripla, deve-se levar em consideração as condições climáticas ocorridas de setembro a novembro (período da maturação e colheita da cevada), em cada um dos anos estudados, principalmente quanto à temperatura e à intensidade pluviométrica (Cochrane, 1993). As temperaturas médias, observadas em 2002 e 2003, foram semelhantes $\left(17,9\right.$ e $17,4^{\circ} \mathrm{C}$, respectivamente) (Embrapa, [s.d.]) e próximas às normais históricas, mas o número de geadas após a floração, consideradas geadas tardias, e o volume de precipitação foram mais elevados em 2003 (Caierão et al., 2005), o que contribuiu para as respostas diferenciadas da germinação dos grãos de um ano para outro e serviu como indicativo de menor qualidade para os grãos obtidos na safra 2003. Isso pode ser justificado pela maior exposição à umidade e por oscilações bruscas de temperatura (Floss, 2004), ocorridas no ano agrícola de 2003. Esses resultados

Tabela 1. Análise de variância da variável germinação, tendo-se considerado os fatores ano, mês e tratamento e suas interações, para os dados obtidos no período de avaliação ${ }^{(1)}$.

\begin{tabular}{lrrrrr}
\hline Fonte de variação & GL & \multicolumn{1}{c}{ SQ } & QM & Valor F & Prob. $>$ F \\
\hline Ano & 1 & 529 & 529 & 1.455 & $<0,0001$ \\
Mês & 11 & 32.207 & 2.927 & 8.059 & $<0,0001$ \\
Tratamento & 7 & 16.895 & 2.413 & 6.643 & $<0,0001$ \\
Ano x Mês & 11 & 2.188 & 199 & 547 & $<0,0001$ \\
Ano x Tratamento & 7 & 80 & 11 & 31 & $<0,0001$ \\
Mês x Tratamento & 77 & 1.812 & 23 & 64 & $<0,0001$ \\
Ano x Mês x Tratamento & 77 & 1.385 & 18 & 49 & $<0,0001$ \\
\hline
\end{tabular}

${ }^{(1)} \mathrm{GL}$ : graus de liberdade; SQ: soma dos quadrados; QM: quadrado médio. 
demonstram que, se o ano agrícola for favorável e as condições de armazenamento forem adequadas, é possível se armazenar grãos de cevada, viáveis para a malteação, por até nove meses.

A germinação da cevada teve comportamento distinto para cada tratamento, dentro de cada mês de avaliação, nos dois anos estudados (Tabelas 2 e 3 ). Em todos os meses, nos dois anos de avaliação, as amostras da TCA apresentaram médias de germinação abaixo de $90 \%$ e foram enquadradas na classe III, conforme o critério de recebimento adotado pelas empresas de fomento do cereal (Tabelas 2 e 3), o que torna evidente o prejuízo proporcionado pela antecipação da colheita sobre a qualidade, em razão da diferença de maturação das espigas e presença de grãos verdes (Sterling et al., 2003). Esta situação é freqüentemente encontrada em lavouras de cevada, em razão da dessincronização do desenvolvimento dos afilhos em relação à planta-mãe (Masle, 1985), consequiência, por exemplo, de adubação de cobertura desbalanceada, acamamento e rebrote (Reunião Anual de
Pesquisa de Cevada, 2005). Assim, como muitos produtores usam o estádio das espigas principais para tomar a decisão da colheita, o reflexo da prática na qualidade é previsível. Nas situações em que a colheita foi antecipada pela aplicação de herbicidas dessecantes (tratamentos 1 a 6), em ambos os anos, a manutenção qualitativa foi muito superior à colheita antecipada sem ação química.

Nas amostras analisadas em 2003, a queda do padrão qualitativo da TCN (tratamento 7) teve início em outubro, quando foi enquadrada na classe II, e foi acelerada nos meses seguintes, classificadas, então, como classe III (Tabela 2). Até o mês de julho, todos os tratamentos com uso de herbicidas dessecantes foram enquadrados na mesma classe que a TCN, com comportamento similar na germinação dos grãos. Somente o tratamento glifosato $1 \mathrm{~L} \mathrm{ha}^{-1}$, em agosto e setembro, demonstrou enquadramento qualitativo inferior aos demais tratamentos com dessecantes e à TCN, evidência de que o estádio usado para a dessecação foi adequado. Os resultados concordam com os de Ellis \& Pieta (1992), que definiram que o pico de tolerância à dessecação ocorre

Tabela 2. Classificação das médias de germinação dos tratamentos, dentro de cada mês de avaliação, conforme o enquadramento qualitativo da indústria cervejeira, no ano de $2003^{(1)}$.

\begin{tabular}{|c|c|c|c|c|c|c|c|c|c|c|c|c|}
\hline Tratamento $^{(2)}$ & Jan. & Fev. & Mar. & Abr. & Maio & Jun. & Jul. & Ago. & Set. & Out. & Nov. & Dez. \\
\hline 1 & $98,0 \mathrm{I}$ & 96,7 I & $95,0 \mathrm{I}$ & $95,0 \mathrm{I}$ & $96,0 \mathrm{I}$ & $96,0 \mathrm{I}$ & $96,5 \mathrm{I}$ & $93,2 \mathrm{II}$ & $93,2 \mathrm{II}$ & $92,1 \mathrm{II}$ & 79,3 III & $76,0 \mathrm{III}$ \\
\hline 2 & $98,0 \mathrm{I}$ & $95,0 \mathrm{I}$ & 95,2 I & $95,0 \mathrm{I}$ & 95,9 I & $96,3 \mathrm{I}$ & $95,0 \mathrm{I}$ & $96,3 \mathrm{I}$ & 96,3 I & $94,8 \mathrm{II}$ & 81,0 III & 73,3 III \\
\hline 3 & $97,1 \mathrm{I}$ & $97,3 \mathrm{I}$ & 96,6 I & 96,4 I & 97,7 I & $98,6 \mathrm{I}$ & $97,0 \mathrm{I}$ & $95,1 \mathrm{I}$ & 95,4 I & $93,2 \mathrm{II}$ & $84,0 \mathrm{III}$ & 80,3 III \\
\hline 4 & 97,7 I & $96,5 \mathrm{I}$ & $97,1 \mathrm{I}$ & $97,1 \mathrm{I}$ & $95,5 \mathrm{I}$ & $95,8 \mathrm{I}$ & $95,3 \mathrm{I}$ & $95,2 \mathrm{I}$ & $95,3 \mathrm{I}$ & 94,9 II & 81,3 III & 77,3 III \\
\hline 5 & $97,8 \mathrm{I}$ & $96,0 \mathrm{I}$ & $96,1 \mathrm{I}$ & $96,1 \mathrm{I}$ & 96,6 I & 96,9 I & 96,0 I & 96,9 I & 96,6 I & 93,8 II & 81,0 III & 76,0 III \\
\hline 6 & 97,4 I & 96,3 I & 97,4 I & 97,4 I & 96,3 I & $96,0 \mathrm{I}$ & $95,0 \mathrm{I}$ & $96,0 \mathrm{I}$ & $96,0 \mathrm{I}$ & 94,4 II & 84,3 III & $77,0 \mathrm{III}$ \\
\hline 7 & $98,0 \mathrm{I}$ & 98,7 I & $98,1 \mathrm{I}$ & $97,1 \mathrm{I}$ & $95,1 \mathrm{I}$ & $95,0 \mathrm{I}$ & $97,0 \mathrm{I}$ & 96,3 I & 96,3 I & 93,3 II & 79,3 III & 72,0 III \\
\hline 8 & 86,9 III & 85,6 III & 80,5 III & 80,5 III & 80,9 III & 81,6 III & 79,3 III & 75,3 III & 75,3 III & $75,5 \mathrm{III}$ & 65,0 III & $60,0 \mathrm{III}$ \\
\hline
\end{tabular}

(1)I, cevada com germinação superior a 95\%; II, cevada com germinação entre 90 e 95\%; III, cevada com germinação inferior a 90\%. (2) 1 : glifosato $1 \mathrm{~L} \mathrm{ha}^{-1}$; 2: glifosato $1,5 \mathrm{~L} \mathrm{ha}^{-1}$; 3: glifosato $2 \mathrm{~L} \mathrm{ha}^{-1} ; 4$ : paraquat $1 \mathrm{~L} \mathrm{ha}^{-1}$; 5: paraquat $1,5 \mathrm{~L} \mathrm{ha}^{-1}$; 6: paraquat $2 \mathrm{~L}^{-1}$, todos aplicados entre os estádios 11.2 e 11.3 da escala de Large (1954); 7: testemunha colheita normal; 8: testemunha colheita antecipada.

Tabela 3. Classificação das médias de germinação dos tratamentos, dentro de cada mês de avaliação, conforme o enquadramento qualitativo da indústria cervejeira, no ano de $2004^{(1)}$.

\begin{tabular}{|c|c|c|c|c|c|c|c|c|c|c|c|c|}
\hline Tratamento $^{(2)}$ & Jan. & Fev. & Mar. & Abr. & Maio & Jun. & Jul. & Ago. & Set. & Out. & Nov. & Dez. \\
\hline 1 & $98,0 \mathrm{I}$ & $95,1 \mathrm{I}$ & 96,7 I & 93,7 II & $96,0 \mathrm{I}$ & $96,3 \mathrm{I}$ & 93,6 II & 92,3 II & 91,4 II & 79,3 III & 76,4 III & 70,0 III \\
\hline 2 & $96,1 \mathrm{I}$ & $95,0 \mathrm{I}$ & 94,1 II & $95,0 \mathrm{I}$ & 95,9 I & 93,6 II & $97,1 \mathrm{I}$ & 95,4 I & 94,3 II & 86,2 III & 73,7 III & 70,1 III \\
\hline 3 & $98,1 \mathrm{I}$ & $97,0 \mathrm{I}$ & 98,2 I & 96,7 I & $98,1 \mathrm{I}$ & 97,2 I & $95,1 \mathrm{I}$ & 92,4 II & $97,0 \mathrm{I}$ & 82,3 III & 82,5 III & $80,1 \mathrm{III}$ \\
\hline 4 & $97,9 \mathrm{I}$ & $97,7 \mathrm{I}$ & $96,7 \mathrm{I}$ & 97,2 I & $96,4 \mathrm{I}$ & $95,0 \mathrm{I}$ & $95,1 \mathrm{I}$ & 95,7 I & $96,1 \mathrm{I}$ & 82,6 III & 78,3 III & $68,1 \mathrm{III}$ \\
\hline 5 & $96,0 \mathrm{I}$ & $97,9 \mathrm{I}$ & $96,1 \mathrm{I}$ & 96,2 I & $96,7 \mathrm{I}$ & 96,6 I & $96,7 \mathrm{I}$ & 93,4 II & $94,1 \mathrm{II}$ & 82,8 III & 76,4 III & $74,1 \mathrm{III}$ \\
\hline 6 & $96,0 \mathrm{I}$ & $95,1 \mathrm{I}$ & 96,7 I & 97,2 I & $96,1 \mathrm{I}$ & $95,0 \mathrm{I}$ & $96,1 \mathrm{I}$ & $94,5 \mathrm{II}$ & $92,8 \mathrm{II}$ & 83,2 III & $77,5 \mathrm{III}$ & $72,1 \mathrm{III}$ \\
\hline 7 & $98,0 \mathrm{I}$ & $98,0 \mathrm{I}$ & 99,2 I & $98,3 \mathrm{I}$ & $96,0 \mathrm{I}$ & $97,4 \mathrm{I}$ & $97,1 \mathrm{I}$ & 93,2 II & 76,3 III & $76,4 \mathrm{III}$ & $70,1 \mathrm{III}$ & $70,1 \mathrm{III}$ \\
\hline 8 & $89,8 \mathrm{III}$ & $86,1 \mathrm{III}$ & 85,6 III & $80,5 \mathrm{III}$ & $80,7 \mathrm{III}$ & $78,2 \mathrm{III}$ & $74,1 \mathrm{III}$ & $74,6 \mathrm{III}$ & 73,4 III & 63,7 III & 58,4 III & $50,3 \mathrm{III}$ \\
\hline
\end{tabular}

(1)I, cevada com germinação superior a 95\%; II, cevada com germinação entre 90 e 95\%; III, cevada com germinação inferior a 90\%. (2) 1 : glifosato $1 \mathrm{~L} \mathrm{ha}^{-1}$; 2: glifosato $1,5 \mathrm{~L} \mathrm{ha}^{-1}$; 3: glifosato $2 \mathrm{~L} \mathrm{ha}^{-1}$; 4: paraquat $1 \mathrm{~L} \mathrm{ha}^{-1}$; 5: paraquat $1,5 \mathrm{~L} \mathrm{ha}^{-1}$; 6: paraquat $2 \mathrm{~L} \mathrm{ha}{ }^{-1}$, todos aplicados entre os estádios 11.2 e 11.3 da escala de Large (1954); 7: testemunha colheita normal; 8: testemunha colheita antecipada. 
algum tempo antes da maturidade fisiológica. Com relação à redução qualitativa ocasionada pelo glifosato, na dose de $1 \mathrm{~L} \mathrm{ha}^{-1}$, não foram encontradas evidências na literatura que justificassem esse comportamento específico, já que, a partir de outubro, a deterioração qualitativa voltou a ser similar à dos demais tratamentos (Tabela 2).

A redução no padrão qualitativo da TCN em outubro, novembro e dezembro foi acompanhada pelos tratamentos com dessecantes. Considerando-se que o critério de classificação da cevada quanto à germinação, aplicado no momento do recebimento da cevada, está diretamente ligado ao preço pago ao produto (Brasil, 1996), pode-se dizer que o uso da dessecação não reduziria a rentabilidade do produtor, uma vez que os tratamentos dessecados pertenceram ao mesmo grupo qualitativo da $\mathrm{TCN}$, em quase todos os meses (Tabela 2).

O ano de 2003 discriminou melhor os tratamentos, e a queda na germinação na TCN iniciou-se mais cedo (agosto), em comparação ao ano de 2002 (Tabela 3). Nesse mês, a TCN foi classificada como pertencente à classe II e, nos quatro meses posteriores, como pertencente à classe III. Os tratamentos glifosato $1 \mathrm{~L} \mathrm{ha}^{-1}$, nos meses de abril e julho, e glifosato 1,5 $\mathrm{L} \mathrm{ha}^{-1}$, nos meses de março e junho, apresentaram classificação qualitativa inferior à TCN, mas sem qualquer tendência de decréscimo. Essas diferenças não são suficientes, para se afirmar que esses produtos, nas dosagens utilizadas, aceleram o processo de deterioração do grão, em relação ao colhido em condições normais, já que houve oscilação no enquadramento das classes qualitativas, ao longo dos meses, e não uma tendência definida, o que contraria os dados de Lacerda et al. (2003) e Baig \& Gamache (2006). Em agosto e setembro, os tratamentos dessecados foram enquadrados no grupo qualitativo equivalente ou superior à TCN (padrão de comparação). Todos os tratamentos testados se igualaram, a partir de outubro, e foram enquadrados no grupo III, de menor qualidade (Tabela 3 ).

Os modelos de regressão linearizados tiveram ajuste $\left(R^{2}\right)$ elevado para todos os tratamentos (com e sem dessecantes), tanto no ano de 2003 (Figura 1) como no ano de 2004 (Figura 2).

Em ambas as safras, o contraste 1 (da dessecação $\mathrm{x}$ TCN) não foi significativo, o que indica que o uso de dessecantes (seja qual for o produto ou dose) não acelera o processo de redução da germinação dos grãos de cevada ao longo do tempo de armazenagem, em relação ao comportamento da TCN (Tabela 4). Esses resultados discordam dos obtidos por Moore \& Jettner (2007), que relatam perdas significativas na qualidade dos grãos desse mesmo cereal, ao longo do tempo, ao se usarem dessecantes em pré-colheita, porém concordam com as das observações de Agostinetto et al. (2001), que não encontraram efeitos prejudiciais significativos. De maneira oposta, o contraste 2 (TCNxTCA) revelou-se significativo nos dois anos de avaliação, indicativo de que o TCA acelera a degradação qualitativa dos grãos de cevada ao longo do tempo, em relação ao TCN (Tabela 4).

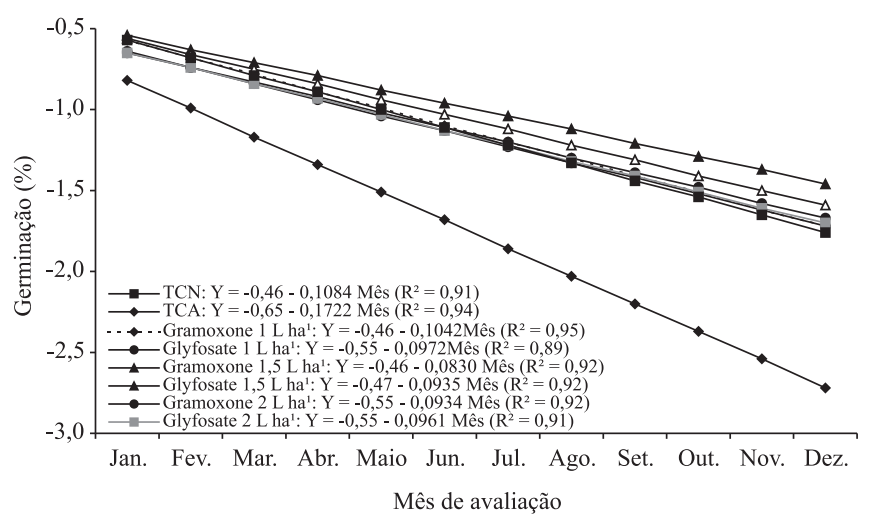

Figura 1. Regressão da variável germinação (dados linearizados), para cada tratamento, de acordo com o mês de armazenamento no ano de 2003 (amostras colhidas em 2002).

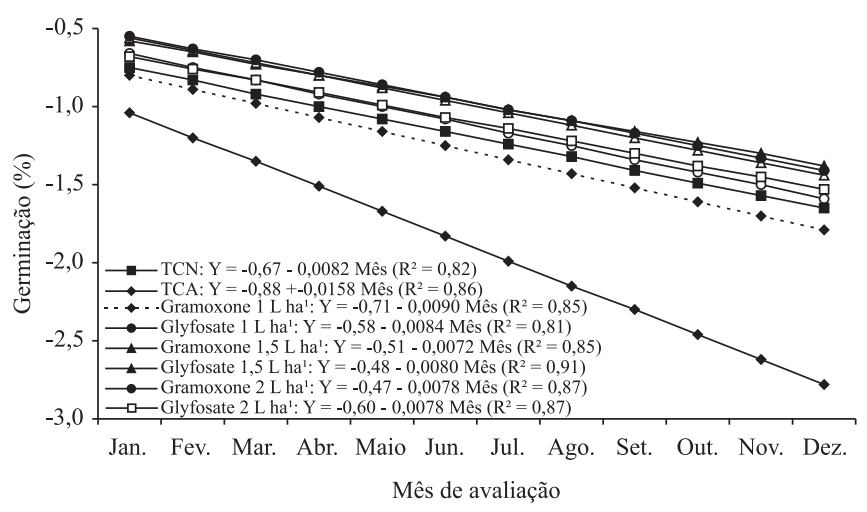

Figura 2. Regressão da variável germinação (dados linearizados), para cada tratamento, de acordo com o mês de armazenamento no ano de 2004 (amostras colhidas em 2003).

Tabela 4. Comparação dos coeficientes angulares das retas linearizadas), dos tratamentos avaliados, nos dois anos de avaliação, a partir de contrastes ortogonais avaliados pelo teste $t$.

\begin{tabular}{llcc}
\hline Contraste $^{(1)}$ & Efeito avaliado & 2003 & 2004 \\
\hline $\mathrm{C}_{1}=\beta_{1}+\beta_{2}+\beta_{3}+\beta_{4}+\beta_{5}+\beta_{6}-6 \beta_{7}$ & Dessecação x TCN & ns & ns \\
$C_{2}=\beta_{7}-\beta_{8}$ & TCN x TCA & $* *$ & $* *$ \\
\hline
\end{tabular}

(1) $\beta$ é o coeficiente angular das retas de cada um dos tratamentos.

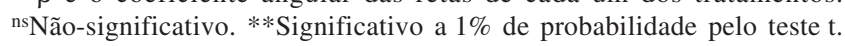




\section{Conclusão}

$\mathrm{O}$ uso dos herbicidas dessecantes paraquat e glifosato, aplicados entre os estádios 11.2 e 11.3 nas doses 1, 1,5 e $2 \mathrm{~L} \mathrm{ha}^{-1}$, não prejudica a germinação de grãos de cevada e não acelera o processo de perda de germinação ao longo do período de armazenagem.

\section{Referências}

AGOSTINETTO, D.; FLECK, N.G.; MENEZES, V.G. Herbicidas não seletivos aplicados na fase de maturação do arroz irrigado. Scientia Agricola, v.58, p.277-285, 2001.

ÁRIAS, G. Mejoramiento genético y producción de cebada cervecera en América del Sur. Santiago: FAO, 1995. 157p.

BAIG, M.N.; GAMACHE, P. Pre-harvest applications of glyphosate for weed control and harvest management. Reduced Tillage Linkages, jul. 2006. Disponível em: http://www.reducedtillage.ca/ article.aspx?a=348. Acesso em: 11 maio 2007.

BRASIL. Ministério da Agricultura, Pecuária e Abastecimento. Portaria nº 691, de 22 de novembro 1996. Define as características de identidade e qualidade da cevada para fins cervejeiros. Diário Oficial da União, Brasília, 22 nov., 1996.

CAIERÃO, E.; SPEROTTO, A.L.; MINELLA, E.; CUNHA, G.R.; PIRES, J.L. Efeito de geadas tardias sobre a qualidade da cevada cervejeira da Ambev, de 2000 a 2004, no Rio Grande do Sul. In: CONGRESSO BRASILEIRO DE AGROMETEREOLOGIA, 14., 2005, Campinas. Anais. Campinas: Unicamp, 2005. (CD-ROM).

CESSNA, A.J.; DARWENT, A.L.; TOWNLEY-SMITH, L.; HARKER, K.N.; KIRKLAND, K. Residues of glyphosate and its metabolite AMPA in field pea, barley and flax seed following preharvest applications. Canadian Journal of Plant Science, v.82, p.485-489, 2002.

COCHRANE, M.P. Effects of temperature during grain development on the germinability of barley grains. Aspects of Applied Biology, v.36, p.103-113, 1993.

ELLIS, R.H.; PIETA FILHO, C. The development of seed quality in spring and winter cultivars of barley and wheat. Seed Science Research, v.2, p.9-15, 1992.

EMBRAPA. Embrapa Trigo. Informações meteorológicas de Passo Fundo em 2002 e 2003. Passo Fundo: Embrapa Trigo, [s.d.]. 2p. Disponível em: http://www.cnpt.embrapa.br/pesquisa/agromet/ index.html. Acesso em: 11 maio 2007.

FLOSS, E. Fisiologia das plantas cultivadas: o estudo que está por trás do que se vê. Passo Fundo: UPF, 2004. 256p.

GOMES, J.L.L. Efeito da aplicação de paraquat e do reglone sobre a incidência de patógenos nas sementes de soja. In: CONGRESSO BRASILEIRO DE FITOPATOLOGIA, 15., 1982, São Paulo. Anais. São Paulo: Sociedade Brasileira de Fitopatologia, 1982. p.27-32.

HANSON, K.M.; GRAF, R.J. A pratical guide for malt barley production. Saskatoon: Saskatchewan Wheat Pool, 2001. Disponível em: http://www.agpro.com/images/maltbarleyguide.pdf. Acesso em: 11 maio 2007.

IBGE. Levantamento sistemático de produção agrícola: 1970 a 2003. Brasília: IBGE, 2007. 71p. Disponível em: http:// www.ibge.com.br/home/estatistica/indicadores/agropecuaria. Acesso em: 11 maio 2007.

INOUE, M.H.; MARCHIORI JÚNIOR, O.; BRACCINI, A.L.; OLIVEIRA JÚNIOR, R.S.; ÁVILA, M.R.; CONSTANTINI, J. Rendimento de grãos e qualidade de sementes de soja após a aplicação de herbicidas dessecantes. Ciência Rural, v.33, p.769$770,2003$.

JACOBSEN, J.V.; PEARCE, D.W.; POOLE, A.T.; PHARIS, R.P.; MANDER, L.N. Abscisic acid, phaseic acid and gibberellin contents associated with dormancy and germination in barley. Physiologia Plantarum, v.115, p.428-441, 2002.

LACERDA, A.L.S.; LAZARINI, E.; SÁ, M.E.; VALÉRIO FILHO, W.V. Armazenamento de sementes de soja dessecadas e avaliação da qualidade fisiológica, bioquímica e sanitária. Revista Brasileira de Sementes, v.25, p.97-105, 2003.

LACERDA, A.L.S.; LAZARINI, E.; SÁ, M.E.; VALTER FILHO, V.V. Aplicação de dessecantes na cultura da soja: antecipação da colheita e produção de sementes. Planta Daninha, v.19, p.381-390, 2001.

LARGE, E.C. Growth stages in cereals. Plant Pathology, v.3, p.128-129, 1954.

MASLE, J. Competition among tillers in winter wheat: consequences for growth and development of the crop. In: DAY, W.; ATKIN, R.K. (Ed.). Wheat growth and modelling. New York: Plenium Press, 1985. p.33-54.

MIGUEL, M.H. Herbicidas dessecantes: momento de aplicação, eficiência e influência no rendimento e na qualidade de sementes de feijão. 2003. 111p. Tese (Doutorado) - Universidade de São Paulo, Piracicaba.

MOORE, J.; JETTNER, R. The effect of glyphosate, paraquat and diquat as a crop topping application on the germination of barley. Merredin: Department of Agriculture and Food, 2002. 40p. (Crop Updates). Disponível em: http://www.agric.wa.gov.au/ cropupdates/2002/weeds/article51.pdf. Acesso em: 11 maio 2007.

REUNIÃO ANUAL DE PESQUISA DE CEVADA, 25., 2005, Passo Fundo. Indicações técnicas para a produção de cevada cervejeira nas safras de 2005 e 2006. Passo Fundo: Embrapa Trigo, 2005. 102p. (Embrapa Trigo. Sistemas de Produção, 2).

REUSS, R.; CASSELLS, J.A.; GREEN, J.R. Malting barley: storage, dormancy and processing quality. In: AUSTRALIAN POSTHARVEST TECHNICALCONFERENCE, 1., 2003, Camberra. Proceedings. Camberra: Stored Grain Research Laboratory, 2003. p.44-48.

STERLING, M.; BAKER, C.J.; BERRY, P.M.; WADE, A. An experimental investigation of the lodging of wheat. Agriculture and Forest Meteorology, v.119, p.149-165, 2003.

Recebido em 16 de maio de 2007 e aprovado em 20 de agosto de 2007 